\title{
Testicular lipomatosis in Cowden's syndrome
}

\author{
Joe B Woodhouse ${ }^{1}$, Brett Delahunt ${ }^{2}$, Sharon F English ${ }^{1}$, Hamish H Fraser ${ }^{3}$ and \\ Martin M Ferguson ${ }^{4}$ \\ ${ }^{1}$ Department of Urology, Christchurch Hospital, Christchurch, New Zealand; ${ }^{2}$ Department of Pathology and \\ Molecular Medicine, Wellington School of Medicine and Health Sciences, University of Otago, Wellington, \\ New Zealand; ${ }^{3}$ Department of Radiology, Christchurch Hospital, Christchurch, New Zealand and \\ ${ }^{4}$ Department of Stomatology, University of Otago, Dunedin, New Zealand
}

\begin{abstract}
Cowden's syndrome is either familial or sporadic and is associated with the predominantly postpubertal development of a variety of cutaneous, stromal and visceral neoplasms. The syndrome is associated with mutations of the PTEN gene and is closely related to Bannayan's syndrome in which macrocephaly and benign tumors, especially lipomas and hemangiomas are pathognomic. In PTEN knockout mice testicular tumors have been reported and for this reason we felt it prudent to examine the testes of our patients with genetically proven Cowden's syndrome. Seven of eight patients who underwent testicular ultrasound were found to have diffuse bilateral hyperechoic lesions. Four patients consented to testicular biopsy and on histological examination multiple foci of adipocytes were found within the testicular interstitium, with no evidence of dysplasia or preclinical malignancy. Immunohistochemical assessment of adipocytes suggested a stromal derivation without evidence of metaplasia from Leydig cells. In one case there was focal atrophy of seminiferous tubules, while in two others there was nodular periorchitis of the tunica albuginea. Biochemical evaluation of testicular function (luteinizing hormone, follicle-stimulating hormone, testosterone, sex hormone binding globulin and free androgen index), prostate-specific antigen and testicular tumor markers were normal, while seminal fluid analysis showed only minor abnormalities. The high incidence of testicular lipomatosis in our adult subjects suggests this to be an important diagnostic criterion for Cowden's syndrome.
\end{abstract}

Modern Pathology (2005) 18, 1151-1156. doi:10.1038/modpathol.3800448; published online 27 May 2005

Keywords: Cowden's disease; testis; fibrosis; fat; lipomatosis; ultrasound

Cowden's syndrome, also known as multiple hamartoma syndrome, is a rare but well-described entity. First reported in $1963^{1}$ and named for the family of the index patient, it is marked by increased cellular proliferation of ectodermal, mesodermal and endodermal tissues. ${ }^{2}$ There is an association with the development of a variety of neoplasms, which may be benign or malignant, and in particular, cancer of the breast, thyroid, endometrium and skin has been described. Facial mucocutaneous lesions comprise the predominant feature of the disease and although the range of cutaneous lesions is numerous, multiple tricholemmomas are considered pathognomic. ${ }^{3}$ In addition, cutaneous papules and mucosal polyps of the large bowel are common findings, with $90 \%$ of patients showing features of the disease by the age of 20 years.

Correspondence: Dr B Delahunt, MD, Department of Pathology and Molecular Medicine, Wellington School of Medicine and Health Sciences, PO Box 7343, Wellington South, New Zealand. E-mail bd@wnmeds.ac.nz

Received 24 February 2005; revised and accepted 12 April 2005; published online 27 May 2005
Cowden's syndrome has an autosomal dominant pattern of inheritance, although it is known to also occur sporadically. ${ }^{3}$ Initial estimates put the incidence of the syndrome at one per million of population; however, more recently this has been revised to one per $200000{ }^{4}$ No cause has been determined as to why this autosomal syndrome remains uncommon, although lowered fecundity and variable phenotypic expression in this population may be a factor. The affected gene in Cowden's syndrome is located on chromosome 10q23 and encodes for a dual-specific lipid phosphatase that is known as PTEN (phosphates and tensin homologue) or MMAC1. ${ }^{5,6}$ PTEN mutations are not confined to inherited syndromes and have been reported in a variety of sporadic malignancies including breast, thyroid, endometrial, renal, bladder and prostate carcinomas and cerebral glioblastoma. ${ }^{7,8}$ In vivo studies indicate that the gene is important in the phosphoinositide 3-kinase/Akt pathway, where the gene product desphosphorylates membrane lipids and thereby functions as a tumor suppressor directly antagonizing pathway activity. ${ }^{8,9}$ This biochemical pathway is important in cell cycle activity and for 
this reason PTEN has a central role in the control of cell proliferation and differentiation, and in apoptosis.

Knockout mice with PTEN deletions/mutations have been studied histologically and in one murine model, mutant testes were found to harbor sparse germ cells, while the mice developed multiple testicular teratomas of various differentiated and undifferentiated forms. ${ }^{10}$ In view of the association of PTEN/MMAC1 mutation and visceral malignancy, including malignancy of the genitourinary tract, ${ }^{7,8}$ and because of the association between PTEN mutations and the development of testicular tumors in a murine model, we felt it prudent to offer our patient with the cowden's syndrome testicular examination in order to exclude premalignant and subclinical malignant testicular lesions. Initial assessment consisted of ultrasound examination, which revealed numerous hyperechoic areas in both testes in all but one of our patients. These ultrasound findings were similar to those recently documented in a single case report. ${ }^{11}$ In this report, the findings were interpreted as being consistent with the appearance of fat-containing hamartomas, although morphologic examination of these lesions was not undertaken.

\section{Materials and methods}

Eight males with phenotypic features of Cowden's syndrome, as well as proven PTEN mutations were included in our series. The ages of the subjects ranged from 16 to 58 years. All subjects had normal external genitalia on physical examination and were of normal sexual development, while none reported any sexual dysfunction. Ultrasound analysis showed multiple hyperechoic areas (Figure 1) in all cases except the 16-year-old, and while the

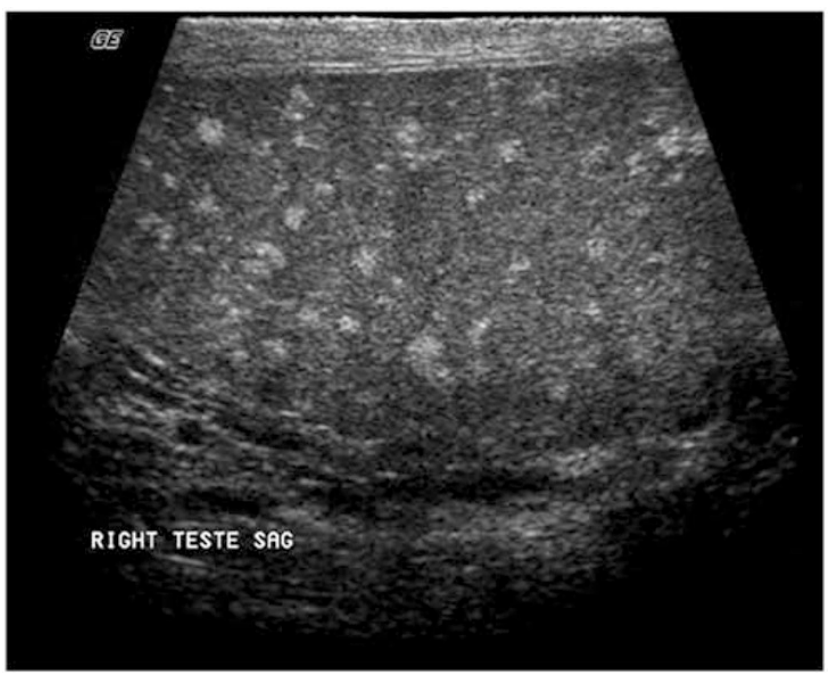

Figure 1 Ultrasound of right testis from case 5. Small hyperechoic areas are scattered throughout the testis. density of these hyperechoic areas varied from patient to patient, they did not appear to increase in either size or number with increasing age. Biochemical evaluation of testicular function (luteinizing hormone, follicle-stimulating hormone, testosterone, sex hormone binding globulin and free androgen index) was undertaken in all cases and evaluation of serum tumor markers ( $\alpha$ fetoprotein, $\beta$-human chorionic gonadotrophin and lactate dehydrogenase) and prostate specific antigen was undertaken in all but the 16-year-old. In addition semen analysis was performed in six of the subjects. Four subjects (cases 2, 3, 5 and 7, Table 1) underwent subsequent open testicular biopsy under general anesthetic. Tissues were fixed in $10 \%$ buffered formal saline overnight and routinely processed. Sections were cut at $4 \mu \mathrm{m}$ thickness and following hematoxylin and eosin staining, were examined by light microscopy.

Additional sections were cut at $5 \mu \mathrm{m}$ for immunohistochemical staining. Following deparaffinization and rehydration, sections were heat treated in citrate buffer, cooled and labeled with antibodies to melan-A (Dako Carpinteria, CA, USA, M7196, 1:20 dilution), calretinin (Novocastra, Newcastle-uponTyne, UK, 1:100 dilution), inhibin- $\alpha$ (Dako, M3609 1:50 dilution) S-100 protein (Dako, Z311, 1:600 dilution) and anti-human muscle actin (Dako M063, 1:100 dilution) using the streptavidin-biotin method.

\section{Results}

\section{Microscopic Findings}

Sections taken from the testicular biopsies showed interstitial lipomatosis consisting of nests of adipocytes within the testicular interstitium. Usually these nests consisted of small groups of several cells (Figure 2), however, occasional nests were larger, with Leydig cell aggregates at the periphery (Figure 3). In one case there was focal hyalinization of seminiferous tubules with loss of germ cell elements and Sertoli cells, and pronounced thickening of the seminiferous tubule basement membrane (Figure 4). In these areas, occasional lymphocytes and plasma cells were seen.

The adipocytes showed positive cytoplasmic immunoexpression for S-100 protein (Figure 5) and were negative for melan-A, calretinin, inhibin- $\alpha$ and muscle actin, while Leydig cells showed positive staining for melan-A, calretinin and inhibin- $\alpha$.

The remainder of the seminiferous tubules showed normal spermatogenesis and contained a normal population of Sertoli cells. No intratubular calcification or intratubular germ cell neoplasia was seen. There was mild edema of the interstitial fibrous tissue of the testis, however the Leydig cells were normal both in morphology and numbers.

In two of the biopsies there was fibromatous/ nodular periorchitis of the tunica albuginea. In one 
Table 1 Biochemistry and seminal fluid results from cases of Cowden's syndrome

\begin{tabular}{|c|c|c|c|c|c|c|c|c|}
\hline & \multicolumn{8}{|c|}{ Case number } \\
\hline & 1 & $2^{\mathrm{a}}$ & $3^{\mathrm{a}}$ & 4 & $5^{\mathrm{a}}$ & 6 & $7^{\mathrm{a}}$ & 8 \\
\hline Age (years) & 58 & 42 & 39 & 39 & 44 & 26 & 40 & 16 \\
\hline PTEN mutation & $40^{\wedge} 41 \operatorname{Ins} A$ & K267X & K237X & K237X & K237X & L139X & IVSC3-IG $>A$ & L139X \\
\hline \multicolumn{9}{|l|}{ Biochemistry } \\
\hline LH (U/l) & 3.0 & 2.0 & 2.8 & 2.0 & 2.0 & 3.7 & 4.0 & 3.5 \\
\hline FSH (U/l) & 5.2 & 3.5 & 3.7 & 2.4 & 3.0 & 3.1 & 1.1 & 2.0 \\
\hline Total T (nmol/l) & 18 & 22 & 16 & 23 & 16 & 30 & 36 & 27 \\
\hline Free $\mathrm{T}(\mathrm{pmol} / \mathrm{l})$ & 478 & 883 & 348 & 646 & 513 & - & 834 & 746 \\
\hline SHBG (nmol/l) & 34 & 42 & 31 & 36 & 33 & 31 & 37 & 23 \\
\hline FAI & 647 & 952 & 516 & 806 & 697 & - & 973 & 1174 \\
\hline PSA (ng/ml) & 2.5 & 1.0 & 1.9 & 0.8 & 1.2 & 0.6 & 0.6 & - \\
\hline$\beta \mathrm{HCG}(\mathrm{mIU} / \mathrm{l})$ & $<5.0$ & $<5.0$ & $<5.0$ & $<5.0$ & $<5.0$ & $<5.0$ & $<2.0$ & - \\
\hline $\mathrm{AFP}(\mu \mathrm{g} / \mathrm{l})$ & $<5.0$ & $<5.0$ & $<5.0$ & $<5.0$ & $<5.0$ & $<5.0$ & $<5.0$ & - \\
\hline $\mathrm{LDH}$ & 152 & 151 & 177 & 192 & 152 & 128 & 180 & - \\
\hline \multicolumn{9}{|l|}{ Semen analysis } \\
\hline Volume (ml) & 1.5 & 2.5 & 7.0 & 0.5 & 0.5 & & 8.0 & - \\
\hline $\mathrm{pH}$ & 8.0 & 8.0 & 8.0 & 8.0 & 8.0 & & 8.0 & - \\
\hline Concentration $\left(\times 10^{6} / \mathrm{ml}\right)$ & 85 & 250 & 82 & 40 & 112 & & 105 & - \\
\hline Motility (\%) & 71 & 66 & 62 & 40 & 50 & & 51 & - \\
\hline Morphology (\% normal) & 73 & 71 & 77 & 43 & 63 & - & 66 & - \\
\hline
\end{tabular}

Glossary and (normal values).

${ }^{\mathrm{a}}$ Testis biopsied.

LH: luteinizing hormone (2-9 U/l); FSH: follicle-stimulating hormone (1-8 U/l); Total T: serum testosterone (9-38 nmol/l); Free T: free serum testosterone (250-800 pmol/l); SHBG: sex hormone binding globulin (9-50 nmol/l); FAI: free androgen index $=$ Total T $\times 100 /$ SHBG $(>400)$; PSA: prostate-specific antigen $(<4.0 \mathrm{ng} / \mathrm{ml})$; $\beta$ HCG: $\beta$ human chorionic gonadotrophin $(<5 \mathrm{mIU} / \mathrm{l})$; AFP: alpha fetoprotein $(<10 \mu \mathrm{g} / \mathrm{l})$; LDH: lactate dehydrogenase $(110-230 \mathrm{U} / \mathrm{l})$.

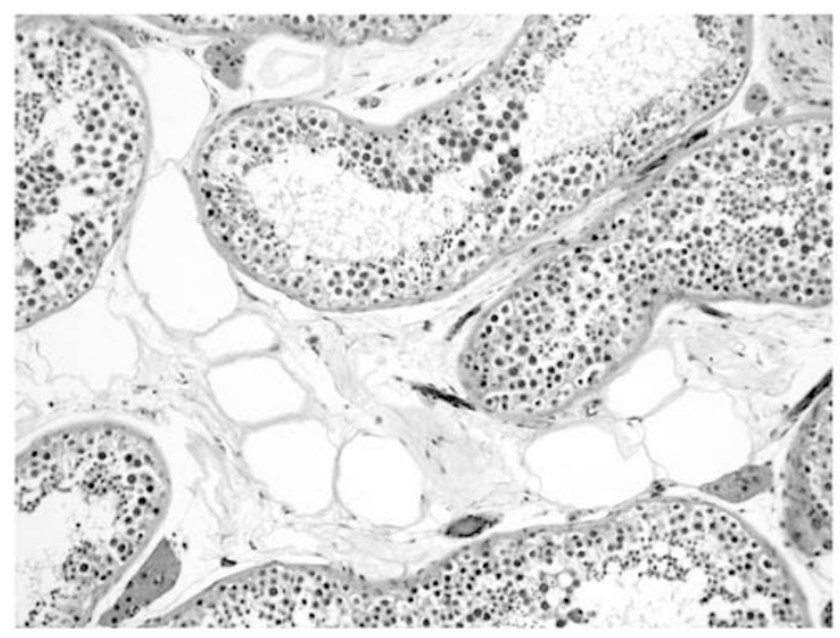

Figure 2 Scattered adipocytes are present within the testicular interstitium. H\&E, $\times 160)$.

case, this was a nodular aggregate of hyalinized paucicellular collagen, while in the other there were nodular collections of hyalinized collagen, which distorted the surface of the tunica albuginea. In the second case, these collections contained foci of dystrophic calcification consisting of multiple concretions exhibiting concentric laminations (Figure 6).

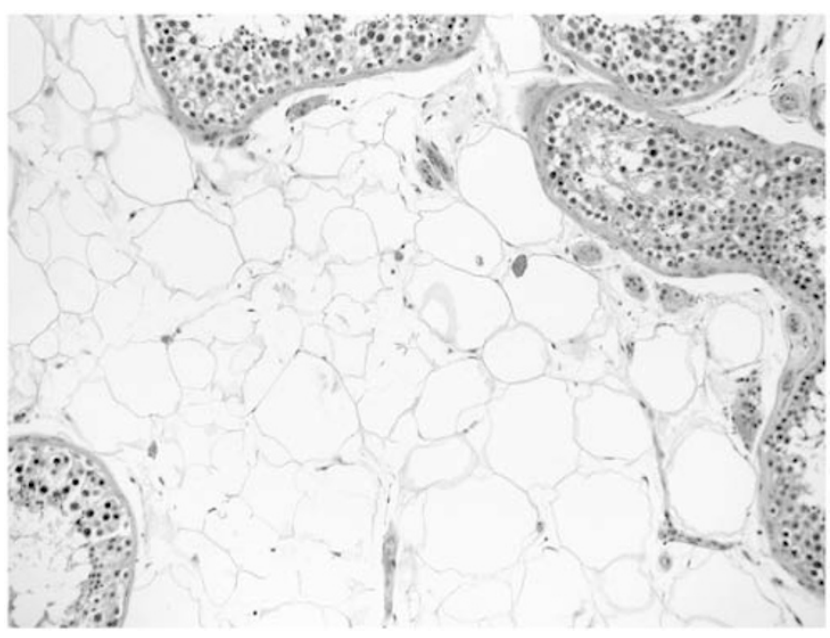

Figure 3 A sheet of adipocytes separates seminiferous tubules. Occasional nests of Leydig cells are present at the periphery $(\mathrm{H} \& \mathrm{E}, \times 240)$.

\section{Biochemistry and Seminal Fluid Analysis}

Serum levels of gonadotrophin, androgen, prostatespecific antigen and tumor marker biochemistry showed no abnormality.

Semen volumes were variable and in two subjects were at the upper limit of normal. In another subject the proportion of motile spermatozoa and sperma- 


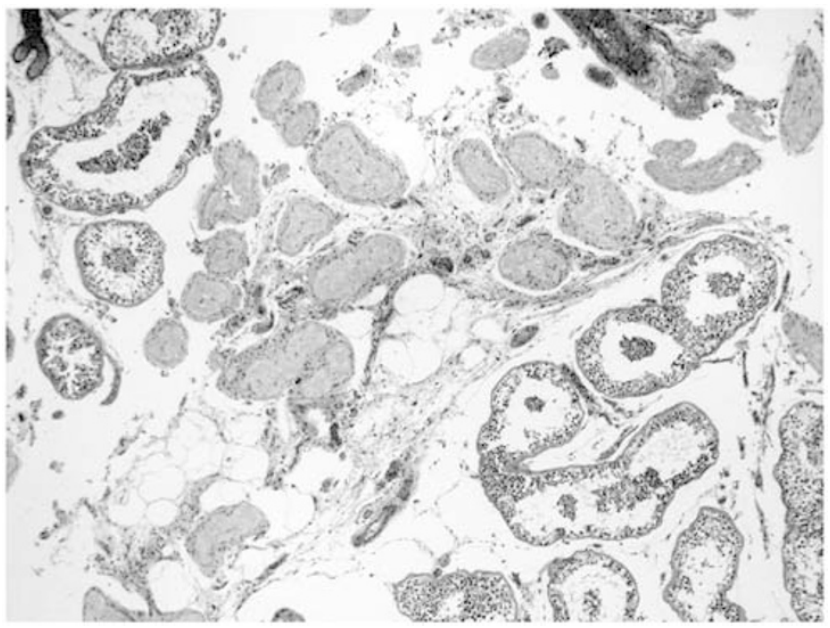

Figure 4 Nests of adipocytes are seen associated with focal atrophy of seminiferous tubules $(\mathrm{H} \& \mathrm{E}, \times 70)$.

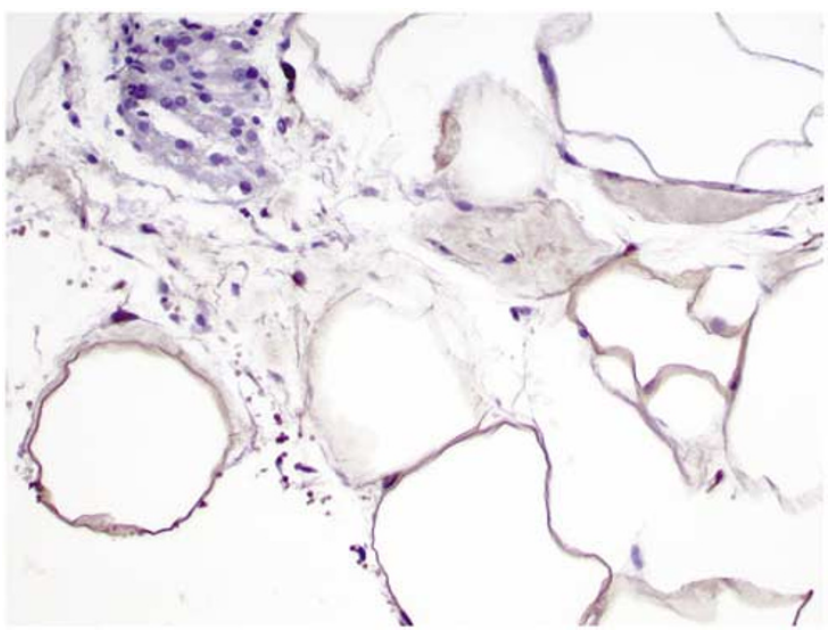

Figure 5 Adipocytes show staining of the cell membrane and nucleus for S-100 protein $(\mathrm{IH} \times 420)$.

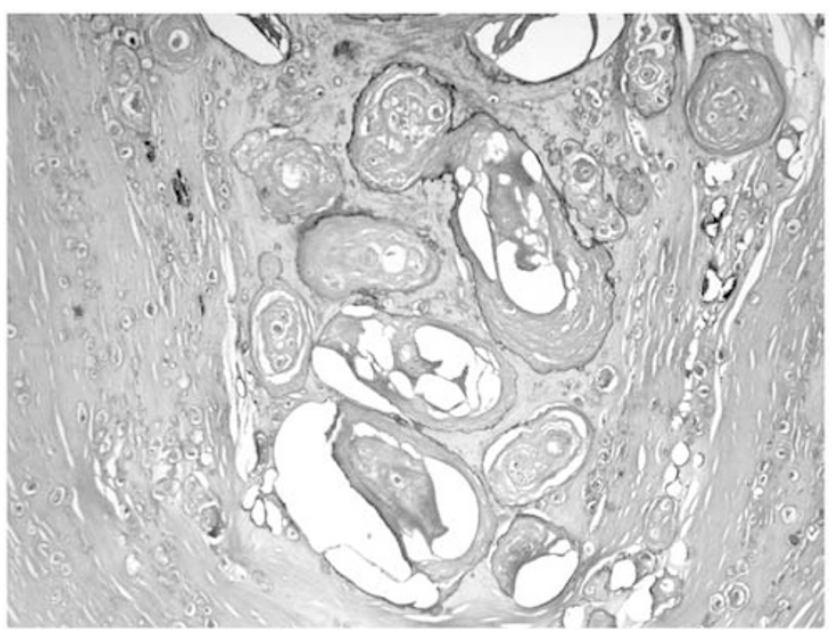

Figure 6 Nodular periorchitis of the tunica albuginea with numerous calcified concretion (Case 2) $(\mathrm{H} \& \mathrm{E} \times 100)$. tozoa with normal morphology was slightly below normal (Table 1).

\section{Discussion}

Cowden's syndrome is associated with the development of multiple neoplastic lesions involving the skin, digestive tract, thyroid gland and breast, and usually presents in adulthood. ${ }^{12}$ While multiple cutaneous tricholemmomas are considered pathognomonic for the syndrome, a wide variety of subcutaneous lesions have been described including papillomas, angiomas, verruciform keratotic papules and lipomas. ${ }^{13}$ Visceral lipomas and aggregates of adipocytes have been reported in Cowden's syndrome, although only rarely. Multiple lipomatous aggregates were seen within the pulmonary interstitium of a patient with Cowden's syndrome who also had multiple lipomatous colonic polyps. ${ }^{12}$ Fat is not normally found in the stroma of non-neoplastic testes and while a feature of some germ cells and stromal tumors, ${ }^{14}$ it has only been previously reported in a single case of postpubertal undescended testis. ${ }^{15}$ Our finding of collections of fat cells within the testis of patients with both clinical and genetic evidence of Cowden's syndrome is of interest and may be a useful diagnostic criterion for the syndrome in adult patients.

Although Cowden's syndrome is well recognized in adults it is poorly characterized in children as the typical lesions appear to develop postpuberty. In this context, it is significant that the 16-year-old patient in our series had no evidence of testicular lesions on ultrasound. There is evidence to suggest that Cowden's syndrome is related to Bannayan's syndrome, which is a childhood syndrome characterized by macrocephaly and benign tumors of mesodermal origin, with lipomas and hemangiomas predominating. Interestingly, both Cowden's and Bannayan's syndromes has been found to occur in the same family and appear to be associated with similar genetic mutations. ${ }^{16}$ In one case of Bannayan's syndrome, interstitial deletion of 10q23.210q24.1 was found, the region that includes the PTEN gene, which is mutated in Cowden's syndrome. ${ }^{13}$ In view of the association of Cowden's and Bannayan's syndrome in the same family, it has been suggested that they are both allelic disorders of the PTEN locus. ${ }^{16,17}$ This putative association is of some relevance to our series, as it has been noted that in Bannayan's syndrome only male subjects develop subcutaneous lipomata. ${ }^{18}$ While all but one of the cases in our series had testicular lesions on ultrasound, the ovary of a female relative with Cowden's syndrome, who had undergone hysterectomy for endometrial carcinoma, contained no interstitial fat (data not shown).

Fatty metaplasia of the testis appears to be a rare event and has been previously reported only 
once in the absence of neoplasia, in the undescended testis of a 37-year-old who was otherwise normal on clinical examination. ${ }^{15}$ Fat cells have been reported in Leydig cell tumors showing a variety of atypical features, which included calcification, ossification and spindle cell proliferation. ${ }^{14}$ In these tumors, immunohistochemical studies suggested that the adipocytes were derived from Leydig cells and that a morphologic evolution from Leydig cells to 'adipocytes' could be determined histologically. In view of these findings, the derivation of the adipocytes in the postpubertal undescended testis is of relevance as they occurred within a nodule of hyperplastic Leydig cells. It would appear that the adipocytes of Cowden's testicular lipomatosis have features of true adipocytes derived from mesoderm, as they are S-100 protein positive although, surprisingly, they are also calretinin negative. Further, they lack the immunoexpression of melan-A and inhibin- $\alpha$ seen in both Leydig cells and the 'adipocytes' of Leydig cell tumors.

The presence of nests of adipocytes within the testis of individuals with Cowden's syndrome does not, in itself, appear to influence fertility. All of the examined testis showed normal spermatogenesis histologically and in five of the six cases semen analysis was within normal limits. In one subject, both spermatozoa motility and percent of normal forms was slightly below normal; however, this would most likely not influence fecundity. In one biopsy there was focal atrophy of seminiferous tubules and this was probably a pressure effect as this testis contained numerous fat deposits on ultrasound examination. Somewhat surprisingly, seminal fluid analysis was normal in this case suggesting that the observed atrophy was confined to a single testicular lobule.

A single lesion on ultrasound examination of the testis is not an uncommon finding; however, multiple and diffuse lesions are usually seen only in the context of microlithiasis, in which foci of dystrophic calcification are present within the lumina of seminiferous tubules. ${ }^{19}$ While there is an association between microlithiasis and synchronous testicular germ cell malignancy, there is no evidence to suggest that the diffuse testicular lesions of Cowden's syndrome are premalignant. A single case of testicular seminoma in a 42-year-old with Cowden's syndrome has been reported ${ }^{20}$ and although the author suggested a possible association, it is more likely that the occurrence of seminoma in this case is sporadic. This is reinforced by the observation that PTEN mutations are not a feature of seminoma. Furthermore, there was no evidence of dysplasia or neoplasia in any of our testicular biopsies and in all of our cases hormone biochemistry was normal and tumor markers showed no evidence of malignancy.

In view of the apparent benign nature of the testicular lesions of Cowden's syndrome we would not recommend that testicular biopsy be undertaken as a routine procedure for these individuals. Once the lesions are diagnosed on ultrasound we recommend that an interval scan be performed in order to confirm stability. All patients should be advised to undertake regular testicular self-examination and seek medical advice if concerned.

\section{References}

1 Lloyd KM, Dennis M. Cowden's disease: a possible new symptom complex with multiple system involvement. Ann Int Med 1963;58:136-142.

2 Weary PE, Gorlin RJ, Gentry WC, et al. Multiple hamartoma syndrome (Cowden's disease). Arch Dermatol 1972;106:682-690.

3 Fistarol SK, Anliker MD, Itin PH. Cowden disease as multiple hamartoma syndrome-cutaneous clue to internal malignancy. Europ J Dermatol 2002;12: 411-421.

4 Eng C. PTEN: One gene, many syndromes. Hum Mutat 2003;22:183-198.

5 Hanson AMN, Fryns JP. Cowden syndrome. J Med Genet 1995;32:117-119.

6 Tsou HC, Ping XL, Xie XX, et al. The genetic basis of Cowden syndrome: three novel mutations in PTEN/ MMAC1/TEP1. Hum Genet 1998;102:467-473.

7 Velickovic M, Delahunt B, McIver B, et al. Intragenic PTEN/MMAC1 loss of heterozygosity in conventional (clear cell) renal cell carcinoma is associated with poor patient prognosis. Mod Pathol 2002;15:479-485.

8 Sansal I, Sellers WR. The biology and clinical relevance of the PTEN tumor suppressor pathway. J Clin Oncol 2004;22:2954-2963.

9 Di Cristofano A, Pesce B, Cordon-Cardo C, et al. PTEN is essential for embryonic development and tumour suppression. Nat Genet 1998;19:348-355.

10 Kimura T, Suzuki A, Fujita Y, et al. Conditional loss of PTEN leads to testicular teratoma and enhances embryonic germ cell production. Development 2003; 130:1691-1700.

11 Lindsay C, Boardman L, Farrell M. Testicular hamartomas in Cowden disease. J Clin Ultrasound 2003; 31:481-483.

12 Solli P, Rossi G, Carbognani P, et al. Pulmonary abnormalities in Cowden's disease. J Cardiovasc Surg 1999;40:753-755.

13 Kuffer R, Rougler M, Laugier P, et al. Cowden's disease-a report on two cases in Swiss families. Rev Stomatol Chir Maxillofac 1979;80:246-256.

14 Ulbright TM, Srigley JR, Hatzianastassiou DK, et al. Leydig cell tumors of the testis with unusual features. Adipose differentiation, calcification with ossification, and spindle-shaped tumor cells. Am J Surg Pathol 2002;26:1424-1433.

15 Honoré LH. Fatty metaplasia in a postpubertal undescended testis: a case report. J Urol 1979;122: 841-842.

16 Perriad J, Saurat JH, Harms. An overlap of Cowden's disease and Bannayan-Riley-Ruvalcaba syndrome in the same family. J Am Acad Dermatol 2000;42: 348-350.

17 Arch EM, Goodman BK, Van Wesep RA, et al. Deletion of PTEN in a patient with Bannayan-Riley-Ruvalcaba 
syndrome suggests allelism with Cowden disease. Am J Med Genet 1997;71:489-493.

18 Gujrati M, Thomas C, Zelby A, et al. BannayanZonana syndrome: a rare autosomal dominant syndrome with multiple lipomas and hemangiomas: a case report and review of literature. Surg Neurol 1998;50:164-168.
19 Kragel PJ, Delvecchio D, Orlando R, et al. Ultrasonographic findings of testicular microlithiasis associated with intratubular germ cell neoplasia. Urology 1991;37:66-68.

20 Mazereeuw-Hautier J, Assouère MN, Moreau-Cabarrot A, et al. Cowden's syndrome: possible association with testicular seminoma. Brit J Dermatol 2004;150:378-379. 